\begin{tabular}{|c|c|c|c|c|}
\hline Date. & Time. & Scale. & Room Temp. & Remarks. \\
\hline Nov. $8 \ldots .$. & $\begin{array}{l}\text { 7:30 A.M. } \\
\text { 8:45 A.M. } \\
\text { 12:00 Noon } \\
\text { 2:30 P.M. } \\
\text { 5:30 P.M. } \\
\text { 6:00 P.M. } \\
\text { 6:14 P.M. } \\
\text { 6:20 P.M. } \\
\text { 8:00 P.M. } \\
\text { 9:15 P.M. } \\
\text { 6:30 A.M. } \\
\text { 8:00 A.M. }\end{array}$ & $\begin{array}{l}23.3 \\
26.7 \\
22.0 \\
19.2 \\
17.4 \\
16.6 \\
15.9 \\
15.8 \\
16.1 \\
16.5 \\
22.7 \\
23.5\end{array}$ & $\begin{array}{l}19.0^{\circ} \mathrm{C} . \\
18.5 \\
19.0 \\
19.2 \\
19.4 \\
19.5 \\
19.5 \\
19.3 \\
19.8 \\
19.8 \\
19.3 \\
19.2\end{array}$ & Moon at zenith $6: 12$ \\
\hline
\end{tabular}

The evidence of this experiment shows that if the earth's gravitational force is balanced against the torque in a quartz fiber, the moon will disturb that balance gradually over 24-hour periods. A maximum decrease of the earth's gravitation occurring with the moon at its upper culmination and a minimum at the moon's lower culmination.

The author expects in the near future to try to detect any lag effect in the gravitation of the moon and the sun.

The facilities of the Laboratory of Physics of the University of Illinois through the courtesy of Professor A. P. Carman were placed at my disposal for this investigation, while the council and help of Dr. C. T. Knipp were a large factor in its success.

Laboratory OF Physics,

UNIVERSITY OF ILLINOIS,

September, I92r.

\title{
On the Electrical Properties of Illium.
}

By Chas. T. Knipp and J. L. Hall.

ILLIUM was first produced in wire form early during the summer of $192 \mathrm{I}$, making possible the measurement of a number of the electrical properties of this remarkable chemically resistant alloy. The wire for these experiments was generously furnished by Professor S. W. Parr, of the Department of Chemistry, University of Illinois. It was of the particular type known as "Illium-B."

The temperature coefficient of illium was found to be $.000479 \mathrm{ohm}$ per degree Centigrade. In this determination a wire of length $147.1 \mathrm{~cm}$. and mean diameter $.96 \mathrm{~mm}$. (corresponding to No. I6 B. \& S. gauge) was used. The range of temperature was from 0 to $70^{\circ} \mathrm{C}$. and the value given above is the mean of 13 observations over $10^{\circ}$ intervals. 
The resistivity, using the same sample on the basis of the resistances measured over the above range of temperature, was found to be, when extrapolated to zero degrees C., 91.6I $\times \mathrm{IO}^{-6} \mathrm{ohms}$.

The largest thermoelectromotive force is produced when illium is coupled with constantin. It produces a smaller thermoelectromotive force when coupled with nickel, and smaller still with german silver; while with platinum, copper and chromel there is but little thermoelectromotive force generated, and with manganin none at all.

The illium-constantin couple over the range o to $400^{\circ} \mathrm{C}$. was found to be almost identical in its behavior with that of copper-constantin.

UNIVERSITY OF ILLINOIS,

August, I92I. 